\title{
Identidade e intimidade: uma tentativa de decifração da poética de Ana Cristina Cesar \\ Daniel Levy CANDEIAS (FFLCH-USP)
}

RESUMO: Uma tentativa de definição da poética de Ana Cristina Cesar por meio da análise semiótica de um texto específico da coletânea Inéditos e Dispersos, publicada postumamente em 1985 .

PALAVRAS-CHAVE: Semiótica; poética; Ana Cristina Cesar.

ABSTRACT: A endeavor of definition from the poetic of Ana Cristina Cesar using semiotic's analysis by one specific text.

KEYWORDS: Semiotics; poetry; Ana Cristina Cesar. 


\title{
Introdução
}

\author{
"olho muito tempo o corpo de um poema \\ até perder de vista o que não seja corpo \\ e sentir separado dentre os dentes \\ um filete de sangue \\ nas gengivas" \\ Ana Cristina Cesar
}

A obra poética de Ana Cristina Cesar não é muito extensa. Além de integrar a antologia 26 poetas hoje (de 1976), em vida, publicou somente Luvas de Pelica, Cenas de Abril e A teus pés. Depois de seu suicídio, em 1983, a reunião de seus escritos inéditos constitui mais um livro, no qual se encontra poesia reunida a prosa: Inéditos $e$ dispersos. É nele que está o objeto de estudo desse trabalho.

Apesar de pequena, sua produção é complexa, o que torna difícil determinar com brevidade uma leitura fechada. Entretanto, pode-se estabelecer alguns aspectos gerais, que ajudam a entendê-la em âmbito geral.

Semelhante a muitos escritores da modernidade, Ana Cristina Cesar faz uso de moldes próprios, indo de encontro à tradição (principalmente classicista), que canoniza formas fixas, como o soneto, o rondó, o madrigal, etc... No conjunto da obra, não é fácil identificar padrões nos seus modos de estrofação e versificação, além da preferência por rimas internas e o uso freqüente de aliterações e assonâncias. Somam-se a isso a prosa poética e os poemas, cujo plano da expressão é muito semelhante ao de prosa:

"Recuperação da adolescência

é sempre mais difícil

ancorar um navio no espaço"

No que diz respeito ao conteúdo, sua poesia também é muito variada. Os temas vão desde questões amorosas e sentimentais a problemas existenciais e metalinguagem. As figuras costumam ser elementos do cotidiano da cidade, incluindo, de modo menos constante, referências à natureza. O ethos do enunciador faz dele um indivíduo sensível, bastante suscetível ao amor (tanto hétero como homossexual), em conflito com o mundo. A construção estética geral provoca o efeito de sentido de intimidade entre o enunciador e enunciatário, figurativizado inclusive pela forma de diário assumida por muitos de seus escritos.

Principalmente por meio da intertextualidade, é possível depreender a imagem de um enunciatário tão atualizado na cultura mundial contemporânea, quanto o enunciador, que se mostra conhecedor da literatura e da música "em voga" na época. Para explicitar alguns nomes importantes, leia-se o seguinte poema, no qual o sujeito poético revela suas influências:

“Índice Onomástico 


\author{
Alvim, Francisco \\ Augusto, Eudoro \\ Bandeira, Manuel \\ Bishop, Elizabeth \\ Buarque, Helô \\ Carneiro, Angela \\ Dickinson, Emily \\ Drabik, Grazyna \\ Drummond, Carlos \\ Freitas Fo., Armando \\ Holiday, Billie \\ Joyce, James \\ Kleinman, Mary \\ Mansfield, Katherine \\ Meireles, Cecília \\ Melim, Angela \\ Mendes, Murilo \\ Muricy, Kátia \\ Paz, Octavio \\ Pedrosa, Vera \\ Rhys, Jean \\ Stein, Gertrude \\ Whitman, Walt \\ Dedicatória \\ E este é para o Armando."
}

Muitos poemas são constituídos pelo que Greimas denomina "fratura". Situações de relevo, motivadas por uma imagem forte, alguém que desperte o interesse, gestos cativantes, atos traumáticos, ou o quer que seja, acaba dando ensejo à descrição de uma cena em verso; às vezes mais subjetiva (detida em figuras de sensações ou temas), às vezes mais objetiva (detida nas figuras do "mundo natural"). O texto selecionado corresponde a esse tipo em que encontramos a ruptura da continuidade do tempo:

\title{
I
}

"Enquanto leio meus seios estão a descoberto. É difícil concentrar-me ao ver seus bicos. Então rabisco as folhas deste álbum. Poética quebrada pelo meio." 
"Enquanto leio meus textos se fazem descobertos. É difícil escondê-los no meio dessas letras. Então me nutro das tetas dos poetas pensando no meu seio."

O poema se divide em duas partes. A primeira trata de uma descrição evidente. O eu lírico está tentando ler, mas sua concentração é abalada pela visão dos bicos de seus próprios seios. Então, ele pára a leitura e começa a rabiscar o álbum, no qual escreve. Ao contrário da anterior, a segunda revela, logo de início, que a cena não é apenas denotativa, porque o paralelismo das duas frases iniciais associa "textos" a "seios" imediatamente.

Outro recurso poético que acentua essa associação está na forma sintática, que possui duplo sentido, em ambas as partes, pela mesma razão. "Meus seios estão a descoberto" e "meus textos se fazem descobertos" podem ser interpretados tanto como ações concomitantes, como objetos diretos do que, nesse caso, seria considerada como oração principal: "enquanto leio". Assim, a relação entre seio e poesia é intensificada, porque já no princípio, "os seios a descoberto são lidos", do mesmo modo como os textos se descobrem.

$\mathrm{Na}$ frase seguinte, o paralelismo continua, na medida em que é tão difícil esquecer a atração aos seios como a dos textos. Ao final, como no trecho anterior, há uma resolução antecedida por "então". Do mesmo modo que a poética se quebra "pelo meio", para que o enunciador "rabisque" (escreva) o álbum, a poesia alheia é lida como própria: "pensando no meu seio".

A explicitação da conotação na segunda parte ocorre, logo no início, por causa da presença de um desencadeador de isotopia, que revela a concomitância de duas leituras: "descobertos". O uso do verbo descobrir ("descobertos") seria mais apropriado ao objeto direto "seios" do que com "textos". "Letras", por sua vez, não podem cobrir esses últimos, podendo ser interpretadas como a blusa ou tecido que os esconderia. Tem-se a leitura do poeta, que escreve e lê, e da mulher que nutre e é alimentada. No último caso, tanto a palavra nutrir como "tetas", em lugar de seio, dão sustento à hipótese sugerida.

Levando em conta a primeira isotopia, constata-se que o poema revela o fato de que o eu lírico se identifica de tal maneira com o que lê, que só consegue fazê-lo reconhecendo a si mesmo. Portanto, esse é o assunto do poema e as duas partes que o compõem referem-se ao âmbito da literatura. A primeira está ligada à produção e a segunda, à recepção. Enquanto num caso, o enunciador encerra a leitura, porque sente atração por seu corpo, sentido necessidade de escrever (rabiscar) sobre isso. Noutro, só é possível dar prosseguimento à leitura, se ele enxergar seus textos em produções alheias: "Então me nutro das tetas dos poetas pensando no meu seio".

$\mathrm{O}$ mesmo ocorre com a isotopia da alimentação. $\mathrm{O}$ eu lírico tem desejo pelo leite de seu próprio seio, e isso dificulta sua nutrição, que só pode ser feita por outrem em analogia com a inspiração pela tradição literária. Contudo, quando ele projeta seu seio nas "tetas" alheias, o problema se soluciona; e tal qual a leitura que flui por meio do reconhecimento de si mesmo, a nutrição se concretiza. A partir disso, pode-se concluir que objeto de valor é "si mesmo", e é só na conjunção com si mesmo a poesia e a alimentação fluem. Assim, no nível fundamental, depreende-se da construção dessas 
duas isotopias a categoria semântica continuidade x ruptura, que enseja um sistema de relações, representado pelo seguinte quadrado semiótico:

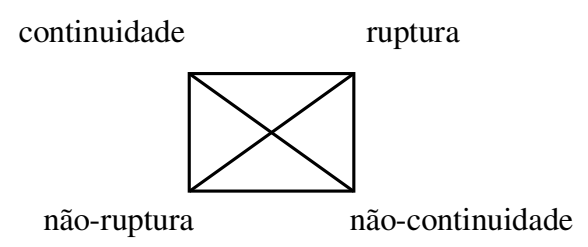

No nível discursivo, os próprios seios ou textos realizam figuras concernentes a "si mesmo". Na isotopia de âmbito literário, o sujeito que quer entrar em disjunção com o objeto de valor, figurativizado pela leitura e "o mundo dos outros escritores", acaba fazendo o contrário, escrevendo os versos do poema e descobrindo seus próprios textos nos de outros. O mesmo se dá com relação à alimentação: o sujeito só consegue se nutrir, quando transforma as "tetas" alheias nos próprios seios, por meio da imaginação entrando em conjunção com os objetos de valor, que parecem ser referentes à ruptura.

Desse modo, é possível notar que "Si mesmo", no início, parece ser referente à ruptura, e assim, indesejado. Afinal, há esforço do sujeito para ler e penetrar no imaginário dos outros escritores, bem como o de resistir aos bicos de seus próprios seios e ao descobrimento de seus textos. Mas o desejo por si próprio, seja ele carnal (seio) ou espiritual (texto), vence esse esforço, promovendo a conjunção, que, supostamente, se faz à revelia do sujeito.

Entretanto, ao contrário do que seria de se esperar diante de um percurso narrativo desse tipo, o tratamento dado à situação final não se dá de forma de negativa, problemática, mas positiva, porque a palavra "então" insere estado de relaxamento. Isto quer dizer que, associada ao percurso, há uma mudança na relação modal do sujeito com o objeto de valor referente. Em outras palavras, o sujeito sofre manipulação para que, ao invés de querer fazer ele mesmo estar em disjunção com o objeto de valor "si mesmo", queira fazer-se conjunto.

Tal manipulação se dá por tentação, na medida em que o desejo por si, espiritual ou carnal, toma lugar do desejo pelo altero, ou seja, é o próprio sujeito, seu próprio corpo e espírito, que o seduz. Ao decorrer do poema, "si mesmo", que não parece, mas é concernente à continuidade (segredo), se revela e muda de valor. $\mathrm{O}$ mesmo ocorre com o eu lírico que parece anti-sujeito de si mesmo, tornando-se depois sujeito do fazer. De modo que na leitura mais forte - sustentada por maior número de palavras (textos, leitura...) e palavras que dizem respeito apenas ao seu lugar semântico: poéticas, poetas - a poetisa acaba mostrando que euforiza o que diz respeito à continuidade, tanto quando produz (leite/texto), como quando recebe.

Pode-se afirmar que essa valorização talvez seja um fundamento estético e o texto tenha algo de poética, semelhante a poemas como "Catar feijão", de João Cabral, e "Profissão de fé", de Olavo Bilac. Como se lê na quarta frase: "Poética quebrada pelo meio". Levando em conta o jogo descrito com objetos diretos nas primeiras frases dos dois blocos, poderia se entender "poesia quebrada pelo meio", no que concerne à 
recepção; e "poética: quebrada pelo meio" no que diz respeito à produção. O que aparentava ser ruptura é somente quebrar ao meio, olhar para si.

Haveria, partindo desse princípio, a sugestão de que o trabalho de Ana Cristina Cesar seria constituído por meio da subjetividade. Segunda ela mesma, esse seria o modo ideal de se relacionar com a boa poesia, na forma de ser influenciada por outros autores ("me nutro das tetas dos poetas pensando no meu seio"); e na escritura, pois o que a leva a escrever ("rabiscar o álbum") é o alheamento do imaginário por meio do excesso de desejo por si mesma.

Além das duas apontadas acima, há outra possibilidade de leitura um pouco mais frágil. Isso porque, diferentemente da isotopia da alimentação e da leitura e produção de poesia, que são sustentadas por palavras como "nutrir", "tetas", no primeiro caso, e "poética", "poetas" e "ler", no segundo; a terceira é desencadeada somente por duas palavras: "bico" e "seio". Quando tais figuras aparecem associadas à exaltação do corpo feminino, sobretudo com esse léxico específico, costumam integrar declarações de amor, discursos sobre a sedução da mulher, etc... Em suma, pode-se dizer que, principalmente no meio literário, "seio" possui conotações sexuais; e a referência metonímica em relação aos bicos intensifica-as.

Outro aspecto que dá base para se depreender sexualidade no poema estudado é o fato de que o eu lírico se sente atraído pelos bicos dos próprios seios, porque eles estão descobertos; e a sedução se dá muitas vezes pelo descobrimento de partes do corpo (note-se que o sujeito poético da autora demonstra sentir atração por pessoas do mesmo sexo ao longo de sua obra). No primeiro trecho, o desejo por si vence a concentração para dar ensejo à escritura. No segundo, esse mesmo tesão, projetado sobre a relação leitora-poetas, é que possibilita uma leitura prazerosa.

Pode-se concluir, a partir dos pontos discutidos, que o poema trata da produção e recepção literárias, dando-lhes conotações de prazer da alimentação e do sexo, por meio da constituição de três isotopias. Sendo assim, o discurso agrega à subjetividade (si mesmo), à poesia e à fluidez, valores de vida, construindo a imagem de Ana Cristina Cesar como uma autora que, apesar de padecer de tantos conflitos existenciais, que ensejam temas e figuras de morte, enxerga na poesia uma espécie de salvação, na qual ela mesma se descobre viva, atraente e atraída.

Assim se explica a estilização epistolar ou de diário de sua obra e a relação de aproximada entre enunciador e enunciatário; o enunciador Ana Cristina Cesar dirige seu discurso a si mesmo. Identidade e intimidade devem percorrer toda a poesia, assumindo por vezes o percurso temático da sinceridade e o tom confessional.:

\section{Este livro}

"Meu filho. Não é automatismo. Juro. É jazz do coração. É prosa que dá prêmio. Um tea for two total, tilintar de verdade que você seduz, charmeur volante, pela pista, a toda. Enfie a carapuça.

E cante.

Puro açúcar branco e blue." 
Fora do âmbito da poesia, na objetividade (outro), o mundo da descontinuidade, o eu lírico se mostra - ao invés de desejoso por si - temeroso e nocivo:

"Estou vivendo de hora em hora, com muito temor. Um dia me safarei - aos poucos me safarei, começarei um safári".

Quando não se conhece a história divulgada da autora, pressupõe-se que esse safári corresponde à caça aos elementos de alteridade. Entretanto, como em sua obra a morte ocupa lugar semelhante ao da poesia, continuidade, encontra-se um movimento de transformação de valores por conta da manipulação que, culminado no suicídio, valoriza o recorrente "si mesmo":

Quando chegar

Quando eu morrer,

Anjos meus,

Fazei-me desaparecer, sumir, evaporar

Desta terra louca

Permiti que eu seja mais um desaparecido

Da lista de mortos de algum campo de batalha

Para que eu não fique exposto

Em algum necrotério branco

Para que não me cortem o ventre

Com propósitos autopsianos

Para que não jaza num caixão frio

Coberto de flores mornas

Para que não sinta mais os afagos

Desta gente tão longe

Para que não ouça reboando eternos

Os ecos de teus soluços

Para que perca-se no éter

O lixo desta memória

Para que apaguem-se bruscos

As marcas do meu sofrer

Para que a morte só seja

Um descanso calmo e doce

Um calmo e doce descanso.

Se se depreender um percurso narrativo do enunciador em sua obra, pode-se afirmar que, do mesmo modo como ocorre com os seios do poema analisado, a morte, vista antes como ruptura, passa a ser vista como continuidade, e a autora, sujeita do ser e do fazer, manipulada por meio da sedução, entra em estado de conjunção com o objeto de valor "si mesmo", figurativizado pelo suicídio. Assim, encontra-se um modo 
semiótico de entender o percurso biográfico, que tornado público em suas distorções e não distorções, interfere na imagem e no ethos do enunciador.

\section{REFERÊNCIAS BIBLIOGRÁFICAS}

BARROS, D.L.P. de.(1988). Teoria do discurso: fundamentos semióticos. .São Paulo, Atual. (1990). Teoria semiótica do texto. São Paulo, Ática.

CESAR, Ana Cristina (1998). Inéditos e dispersos. São Paulo, Ática. (1998). A teus pés. São Paulo, Ática.

FIORIN, J. L. (1988). Linguagem e ideologia. São Paulo, Ática. (1989). Elementos de análise do discurso. São Paulo, Contexto/EDUSP. (1996). As astúcias da enunciação. São Paulo, Ática.

GREIMAS, A. (s.d.). Semântica estrutural. São Paulo, Ática. \& COURTÉS, J. (s.d.). Dicionário de semiótica. São Paulo, Ática. e outros (1975). Ensaios de semiótoca poética. São Paulo, Cultrix/EDUSP. e outros (1977). Semiótica narrativa e textual. São Paulo, Cultrix/EDUSP. \& FONTANILLE, J. (1993). Semiótica das paixões. São Paulo, Ática.

JAKOBSON, Roman (2004). Lingüística. Poética. Cinema. Perspectiva, São Paulo. PIETROFORTE, Antônio Vicente Seraphim (2003). "Ação e paixão no esquema narrativo". In: Cadernos de discussão do centro de pesquisas sociossemióticas. São Paulo, PUC.

\section{Como citar este artigo:}

CANDEIAS, Daniel Levy. Identidade e intimidade; uma tentativa de decifração da poética de Ana Cristina Cesar. Estudos Semióticos, Número 3, São Paulo, 2007. Disponível em <www.fflch.usp.br/dl/semiotica/es>. Acesso em "dia/mês/ano". 